\title{
Maternal risk factors and perinatal outcomes in fetal growth restriction using obstetric Doppler in South Kerala, India
}

\author{
Heera Shenoy T. ${ }^{1 *}$, Sonia X. James ${ }^{2}$, Sheela Shenoy T. ${ }^{3}$
}

\begin{abstract}
${ }^{1}$ Department of Obstetrics and Gynecology, ${ }^{2}$ Department of Radiodiagnosis, Travancore Medical College, Kollam, Kerala, India

${ }^{3}$ Department of Obstetrics and Gynaecology, Government Medical College, Trivandrum, Kerala, India
\end{abstract}

Received: 07 November 2018

Accepted: 24 November 2018

\author{
*Correspondence: \\ Dr. Heera Shenoy T., \\ E-mail: heerarprabhu@gmail.com
}

Copyright: (c) the author(s), publisher and licensee Medip Academy. This is an open-access article distributed under the terms of the Creative Commons Attribution Non-Commercial License, which permits unrestricted non-commercial use, distribution, and reproduction in any medium, provided the original work is properly cited.

\begin{abstract}
Background: Fetal Growth Restriction (FGR) is the single largest contributing factor to perinatal morbidity in nonanomalous foetuses. Synonymous with Intrauterine Growth Restriction (IUGR), it is defined as an estimated fetal weight less than the10th percentile. Obstetric Doppler has helped in early detection and timely intervention in babies with FGR with significant improvements in perinatal outcomes. Hence, authors evaluated the maternal risk factors and diagnosis-delivery intervals and perinatal outcomes in FGR using Doppler.

Methods: This research conducted in a tertiary care hospital in South Kerala included 82 pregnant women who gave birth to neonates with birth weight less than the 10th percentile over a period of 1 year (Jan 1, 2017-Dec 31, 2017). Socio-demographic, maternal risk, Diagnosis- delivery interval in FGR and neonatal morbidities were studied.

Results: Mean GA at diagnosis in weeks was 34.29 and 35.19 respectively for abnormal and normal Doppler respectively ( $p$ value-0.032). The mean birthweight in Doppler abnormal FGR was $272.34 \mathrm{~g}$ lesser than in Doppler normal group ( $\mathrm{p}$ value-0.001). Growth restricted low birth weight neonates had Doppler pattern abnormalities ( $\mathrm{p}$ value-0.0009). FGR <3rd percentile and AFI <5 had abnormal Doppler (OR:6.7). Abnormal biophysical profile (OR:14) and Non-Reactive NST (OR:3.5) correlated with abnormal Doppler. Growth restricted with normal Doppler had shorter NICU stays than with abnormalities ( $p$ value-0.003). Term FGR went home early than early preterm. ( $p$ value-0.001).

Conclusions: Abnormal Doppler velocimetry is significantly associated with earlier FGR detection, shorter decisiondelivery interval, reduction in the mean birthweight and longer NICU stay. Hence, Umbilical artery Doppler and Cerebroplacental index is an integral part of in-utero fetal surveillance to identify impending fetal hypoxia, appropriate management, optimising the timing of delivery and improve perinatal health in FGR.
\end{abstract}

Keywords: Abnormal, Birthweight, Centile, Doppler, Fetal, Growth, Intrauterine, Neonatal, Normal, Restriction

\section{INTRODUCTION}

Fetal Growth Restriction or Intrauterine growth restriction (IUGR) refers to a foetus that has failed to achieve its genetically determined growth potential and it remains one of the prime challenges in maternity care. ${ }^{1,2}$ It is defined as an estimated birth weight of less than $10^{\text {th }}$ percentile. $^{3}$ Nearly $75 \%$ of affected babies are born in Asia. IUGR can lead to increased perinatal morbidity and mortality and impaired neurodevelopment. ${ }^{4}$ There is a high incidence of intrauterine fetal demise, intrapartum fetal distress and operative deliveries in FGR. In Early preterm FGR, iatrogenic prematurity is a pertinent issue. While in late preterm FGR/ early term risks of intrapartum fetal distress and demise is primary concern. Adverse perinatal outcomes were noted in severe FGR $\left(<3^{\text {rd }}\right.$ percentile). FGR is associated with Doppler signs suggesting hemodynamic redistribution as a reflection of 
fetal adaptation to undernutrition, hypoxia, histological and biochemical signs of placental disease and a higher risk of preeclampsia. ${ }^{5}$ Maternal, fetal and uteroplacental causes contribute to FGR. Prediction of risk, timely detection of compromised foetus, strict surveillance and optimising time for delivery is the main aim of antenatal care. ${ }^{6}$ Ultrasonogram is frequently done in antenatal period to assess fetal size (estimated baby weight) through serial fetal biometry measurements. Biophysical Profile (BPP) and Amniotic fluid index (AFI). The combination of these with Obstetric Doppler is the best available tool for identification of small foetus at risk of adverse outcomes. Doppler studies are non-invasive and involve Maternal Uterine arteries (Ut A), Fetal Umbilical artery (UA) for the placenta, Middle cerebral artery (MCA) for preferential brain perfusion and Cerebroplacental Ratio. ${ }^{7,8} \mathrm{CPR}$ is calculated by dividing the middle cerebral artery (MCA) PI by the UA Doppler PI and reflects in a combined fashion mild increases in placental resistance with mild reductions in fetal brain vascular resistance. $^{9}$ As IUGR worsens, Doppler abnormality in these vascular territories also deteriorate suggesting a sequential pattern of disease progression accelerated by hypertension. ${ }^{10}$ Meta- analysis and randomised controlled trials confirm that the use of umbilical artery Doppler abnormality is associated with significant reduction in perinatal mortality. ${ }^{8}$ Before 34 weeks, FGR associated with Doppler abnormality affects Umbilical artery S/D ratio $>3.0$ followed by worsening of Doppler manifested as absent end diastolic flow (AEDF) and reversal of end diastolic flow (REDF). Near term, when umbilical artery changes are subtle, decreases in MCA Doppler indices and reversal of CPR is noted. Doppler velocimetry not only decides the optimum time of delivery but also the optimum mode of delivery. Among foetuses below the 10th centile, those with an EFW less than third centile have a much higher risk of adverse perinatal outcome irrespective of the CPR and Ut a Doppler indices ${ }^{11}$. So, the present research was undertaken to evaluate the sociodemographic variables, maternal risk factors, diagnosis-delivery interval, mode of delivery, birthweight and indications of operative delivery in FGR. Perinatal morbidity was assessed in terms of NICU stay, need for resuscitation and morbidities.

\section{METHODS}

Of the 972 deliveries with 980 neonates, 82 women with neonates less than the 10th centile were recruited for this study. This study was conducted in Department of Obstetrics and Gynaecology, Travancore Medical College, a tertiary care teaching hospital in South Kerala from January 2017 to December 2017. The study population consisted of 82 women with singleton pregnancies who gave birth to neonates with birthweights less than the $10^{\text {th }}$ centile (FGR). New-borns with birth weight below $10^{\text {th }}$ percentile for gestational age on the chart of fetal growth were classified as having fetal growth restriction.

\section{Inclusion criteria}

- Singleton pregnancy

- Gestational age more than 28 weeks

- IUGR diagnosed with Ultrasound and evaluated with Obstetric Doppler

- Normal fetal anatomy

- Delivered at Travancore Medical College and also had NICU care.

\section{Exclusion criteria}

\section{- PPROM}

- Gestational age $>28$ weeks

- Fetus with chromosomal anomalies

- Multifetal gestation with IUGR.

The data on birth was obtained from the computerised database maintained in the hospital information system of Travancore Medical College. Only cases with recorded birthweights and gestational age at the time of delivery (determined by either date of LMP OR dating scan) were included in the final data base. Once FGR was diagnosed, the women underwent Doppler studies of Maternal uterine artery and Fetal umbilical artery and middle cerebral arteries. Gestational age at FGR diagnosis and delivery were noted. Antenatal steroid administration was given to women as per NIH guidelines. In a structured questionnaire, maternal age, domicile, parity, morbidities, sociodemographic details, infertility treatment, previous obstetric career, Gestational age at diagnosis and delivery of FGR were noted. Mode of Delivery and if Caesarean delivery, the indication was noted. All these patients were kept under strict surveillance till confinement and were monitored with CTG, BPP and Doppler velocimetry study. Decision to deliver them was taken if 1) gestational age of 37 weeks, 2) absent end diastolic flow, reverse end diastolic flow, 3) worsening of maternal condition like HELLP, Imminent eclampsia, uncontrolled hypertension 4) oligohydramnios (AFI $<5)$. The neonatal outcome was evaluated in terms of birthweight, Apgar, NICU admission, need to resuscitation, length of NICU stay and morbidities like sepsis, respiratory distress and hyperbilirubinemia. Ultrasound parameters like EBW, AFI, BPP were looked into along with Doppler studies of maternal uterine artery and fetal umbilical artery and middle cerebral arteries and Cerebroplacental indices. The antenatal Doppler evaluation results were compared with birthweights and neonatal outcome like NICU admissions, length of NICU stay, need for ventilator, AFI, BPP, NST and centiles. The length of NICU stay was used to assess the neonatal morbidity. NICU stay of 5 days, 6-10 days and 10 days corresponded to mild, moderate and severe neonatal morbidity respectively.

\section{Statistical analysis}

All the data was entered into Microsoft excel software and analysed using SPSS16 for windows. 
Descriptive analysis was done. Chi Square/ Fischer Exact has been used to find the significance of study parameters and $\mathrm{P}$ value of $<0.05$ was considered significant.

\section{Interpretation of Doppler findings}

Doppler was considered abnormal when

- Uterine artery (on side of placenta) Mean RI $>0.56$ or $\mathrm{S} / \mathrm{D}$ ratio $>2.6$.

- Umbilical Artery

$\circ \quad \mathrm{S} / \mathrm{D}$ ratio $>3$.

- S/D value $>95^{\text {th }}$ percentile of reference values.

- If the diastolic flow was absent (AEDF) or reversed (REDF).

- $\quad$ Middle Cerebral Artery

- MCA/UA PI ratio (CPI) or less than 2SD.

- MCA/UA, S/D ratio<1.

\section{RESULTS}

Out of the 972 deliveries, 82 subjects were recruited in this study.

\section{Sociodemographic profile and FGR}

Majority of mothers were in $25-29(43.9 \%)$ age group with $41.46 \%$ first time mothers. $46 \%$ had one live child and $12.2 \%$ had two live children. 25 subjects gave past $\mathrm{h} / \mathrm{o}$ abortion.

FGR was noted in 8 of these women in their previous pregnancy.81.7\% were from urban setup. There were 22 women $(26.8 \%)$ referred to our tertiary centre for high risk care. $29.3 \%$ of subjects had received treatment for infertility.

Table 1: Socio-demographic profile of FGR.

\begin{tabular}{|lll|}
\hline Characteristic & Frequency $(\mathbf{n = 8 2})$ & $\%$ \\
\hline Maternal age (years) & & \\
\hline$<20$ & 2 & 2.44 \\
\hline $20-24$ & 18 & 21.95 \\
\hline $25-29$ & 36 & 43.90 \\
\hline $30-34$ & 20 & 24.39 \\
\hline$>35$ & 6 & 7.32 \\
\hline Gravida & & \\
\hline G 1 & 34 & 41.46 \\
\hline G 2 & 38 & 46.34 \\
\hline G 3 & 10 & 12.20 \\
\hline Domicile & & \\
\hline Urban & 67 & 81.7 \\
\hline Rural & 15 & 18.3 \\
\hline Status of Subject & & \\
\hline Booked & 60 & 73.2 \\
\hline Referred & 22 & 26.8 \\
\hline Treated for infertility & \\
\hline Yes & 24 & 29.3 \\
\hline No & 58 & 70.7 \\
\hline
\end{tabular}

\section{Maternal risk factors and FGR}

Coming to maternal morbidities leading to FGR, 24.39\% were Hypertensive disorders of Pregnancy followed closely by thyroid dysfunction (21.95\%), anaemia $(19.51 \%)$ and Gestational diabetes (14.63\%). There were no comorbidities in $14.63 \%$. Eclampsia/ imminent eclampsia and HELLP required magnesium sulphate in 8 cases. There was a near miss mortality (HELLP). Severe Anaemia requiring blood transfusion were three in this study. Bronchial Asthma and a heart disease complicated three of FGR mothers.

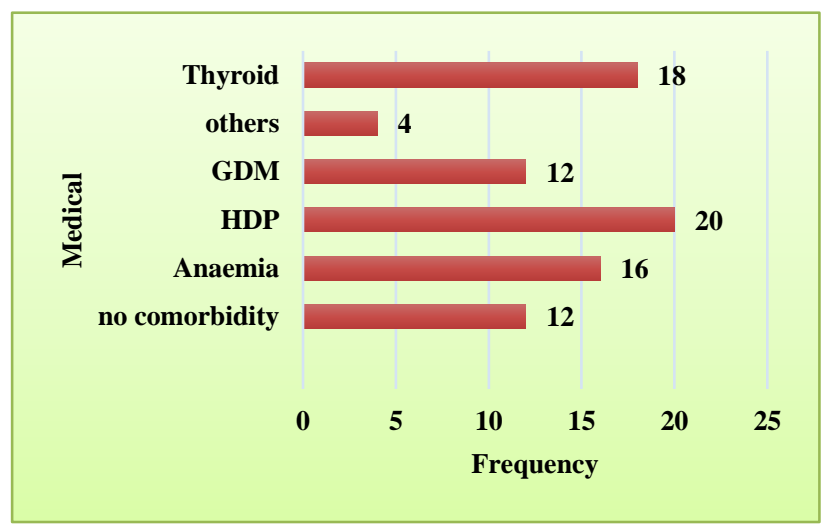

Figure 1: Maternal morbidities and FGR.

\section{Diagnosis-delivery delay and FGR}

FGR were diagnosed in $60.97 \%$ during $34-36.6$ weeks of gestation followed by $19.51 \%$ as early preterm (31-33.6 weeks). There were $17.07 \%$ FGR diagnosed in $>37$ weeks group. Two extreme preterm diagnosed <30.6 weeks were delivered as emergency due to absent end diastolic flow. $32.12 \%$ were delivered between 34-36.6 in view of fetal and maternal comorbidities. $14 \%$ of growth restricted foetuses were terminated $<33.6$ weeks. Hence diagnosis-delivery interval of $<48 \mathrm{hrs}$ was noted in $32.92 \%$ of FGR foetuses. $39.02 \%$ were delivered in $3-7$ days. In $13.41 \%$ FGR, decision was delayed in view of normal Doppler parameters and good in-utero surveillance.

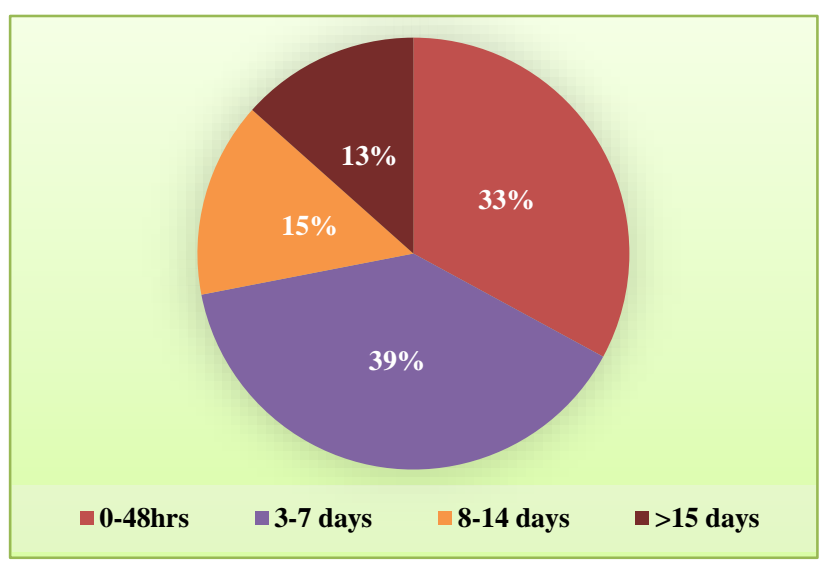

Figure 2: Diagnosis-delivery interval in FGR. 


\section{Mode of outcomes and FGR}

Fetal cause as a reason to deliver was noted in $63.41 \%$ due to fetal distress, non-reassuring fetal heart rates, severe oligoamnios, Doppler abnormality and meconium stained liquor.36.58\% were terminated for maternal reasons with severe preeclampsia, impending eclampsia and eclampsia, HELLP. Failed induction with PROM and unfavourable cervix and previous caesarean added to the burden of operative deliveries. Among the mode of delivery, Caesarean delivery accounted for the majority $(75.60 \%)$ of FGR terminations Emergency caesareans were $32.25 \%$. Only $24.40 \%$ were normal deliveries. Among 20 inductions and 7 spontaneous labours, there were 17 normal deliveries, 3 operative deliveries (vacuum extraction). 7 failed inductions resulted from induced labour. The indications of Cesarean delivery are given in a bar diagram.

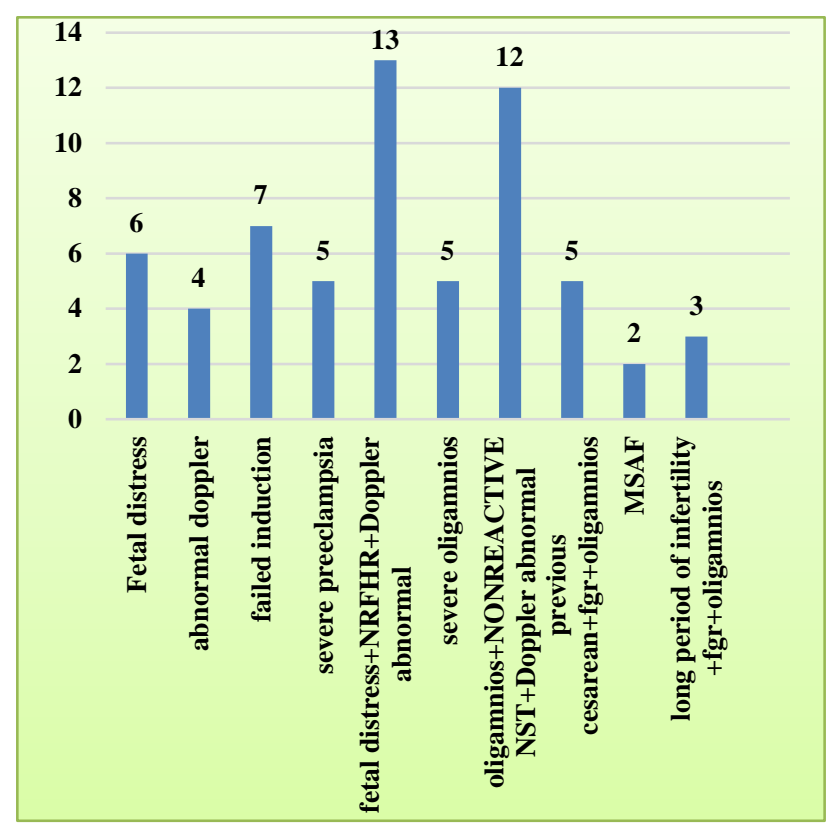

Figure 3: Cesarean delivery and FGR indications.

\section{Birthweight and Doppler in FGR}

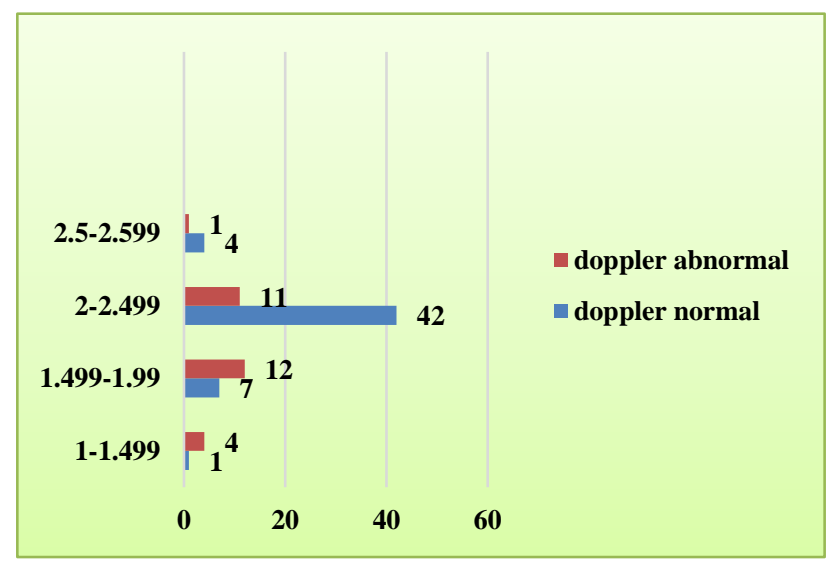

Figure 4: Birth weights and Doppler.
Birthweight from 2-2.499 $\mathrm{kg}$ constituted 53 neonates $(64.63 \%)$ followed by $1.5-1.999 \mathrm{~kg}(23.17 \%) .6 .09 \%(\mathrm{n}=5)$ each had birthweight $<1.499 \mathrm{~kg}$. $66.6 \%$ of babies with birthweight $<2.5 \mathrm{~kg}$ had Doppler abnormal pattern. Doppler abnormality was statistically significant in low birth weight babies with FGR (p value-0.0009).

\section{Neonatal morbidity and FGR}

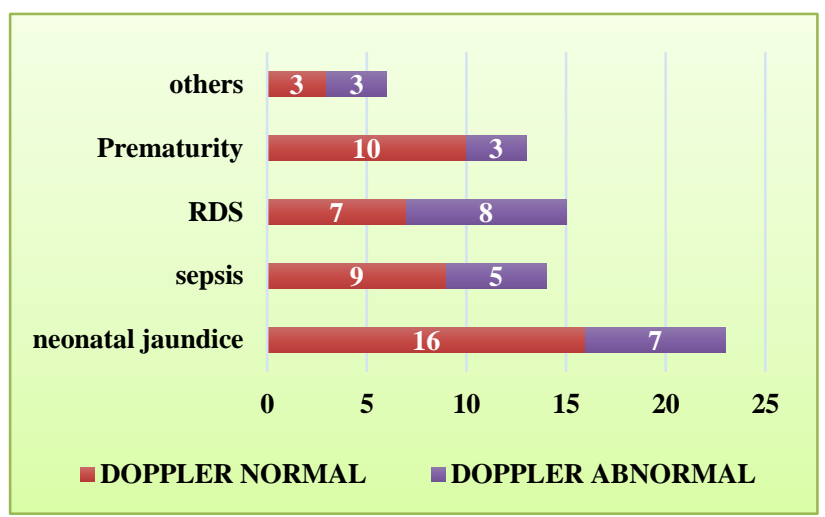

Figure 5: Distribution of neonatal morbidity in FGR.

NICU admissions were needed in 71 neonates $(86.58 \%)$. Need to resuscitate were needed in $13.41 \%$ with need of Ventilator and CPAP. Neonatal morbidity in terms of NICU stay were grouped into mild ( $<5$ days), moderate (6-10days) and severe ( $>10$ days). Term FGR had shorter NICU stay and early preterm $(59.18 \%)$ had longer NICU stay due to neonatal morbidities necessitating prolonged intensive care (p value:0.001). Sepsis, hyperbilirubinemia, respiratory distress syndrome, prematurity, hypocalcaemia, hypoglycaemia, hypothermia were the neonatal morbidities in our growth restricted. Distribution of neonatal morbidities in Doppler normal and abnormal groups are given in Figure 5.

Table 2: Gestational age and neonatal morbidity in FGR.

\begin{tabular}{|llllll|}
\hline $\begin{array}{l}\text { FGR } \\
\text { (gestational } \\
\text { age) weeks }\end{array}$ & $\mathbf{N}$ & $\begin{array}{l}<\mathbf{5} \\
\text { days }\end{array}$ & $\begin{array}{l}\mathbf{5 - 1 0} \\
\text { days }\end{array}$ & $\begin{array}{l}>\mathbf{1 0} \\
\text { days }\end{array}$ & \\
\hline $28-30.6$ & 02 & 0 & 0 & 2 & $\begin{array}{l}\text { Chi } \\
\text { square }\end{array}$ \\
\hline $31-33.6$ & 11 & 01 & 3 & 7 & 32.297 \\
\hline $34-36.6$ & 25 & 8 & 10 & 7 & P value \\
\hline 37 & 33 & 25 & 7 & 1 & 0.001 \\
\hline
\end{tabular}

\section{Doppler abnormalities and other parameters}

Among 82 growth restricted foetuses, 54 of them had normal Doppler patterns $(65.85 \%)$ and 28 had abnormal Doppler patterns (34.15\%). Those with Amniotic fluid index $<8 \mathrm{~cm}$ had 3.7-fold risk of Doppler abnormality in FGR (p value-0.016). Nonreactive NST increased the Odds by 3.5 of Doppler abnormality necessitating imminent delivery. ( $\mathrm{p}$ value-0.010). FGR less than third 
centile multiplied the risk of abnormal Doppler patterns by 6.7 times when compared to birthweight less than $10^{\text {th }}$ centile ( $p$ value-0.001). Biophysical profile score $<8$ carried 14.2 times risk of Doppler abnormality in growth restricted foetuses ( $\mathrm{p}$ value-0.001).

Table 3: Doppler and AFI, BPP, NST, Apgar, NICU admission and centile in FGR.

\begin{tabular}{|c|c|c|c|c|c|c|c|}
\hline \multirow{3}{*}{ Variable } & \multirow{2}{*}{\multicolumn{2}{|c|}{ Doppler }} & \multirow{2}{*}{ Odds Ratio } & \multicolumn{2}{|c|}{ 95\% Confidence Interval } & \multirow{2}{*}{ Chi square } & \multirow{2}{*}{$\mathrm{p}$ value } \\
\hline & & & & Lower & Upper & & \\
\hline & Normal & Abnormal & \multirow{4}{*}{3.7} & \multirow{4}{*}{1.232} & \multirow{4}{*}{11.298} & \multirow{4}{*}{5.808} & \multirow{4}{*}{0.016} \\
\hline Amniotic fluid & & & & & & & \\
\hline $\mathrm{AFI}>8 \mathrm{~cm}$ & $47(87.0 \%)$ & $18(64.3 \%)$ & & & & & \\
\hline $\mathrm{AFI}<8 \mathrm{~cm}$ & $07(13.0 \%)$ & $10(35.7 \%)$ & & & & & \\
\hline \multicolumn{3}{|l|}{ NST } & \multirow{3}{*}{3.5} & \multirow{3}{*}{1.314} & \multirow{3}{*}{9.325} & \multirow{3}{*}{6.571} & \multirow{3}{*}{0.010} \\
\hline Reactive & $42(77.8 \%)$ & $14(50.0 \%)$ & & & & & \\
\hline Nonreactive & $12(22.2 \%)$ & $14(50.0 \%)$ & & & & & \\
\hline \multicolumn{3}{|l|}{ BPP } & \multirow{3}{*}{14.2} & \multirow{3}{*}{4.614} & \multirow{3}{*}{43.542} & \multirow{3}{*}{25.660} & \multirow{3}{*}{0.001} \\
\hline$<8$ & $07(13.0 \%)$ & $19(67.9 \%)$ & & & & & \\
\hline$>8$ & $47(87.0 \%)$ & $09(32.1 \%)$ & & & & & \\
\hline \multicolumn{3}{|l|}{ NICU } & \multirow{3}{*}{0.38} & \multirow{3}{*}{0.077} & \multirow{3}{*}{1.917} & \multirow{3}{*}{1.440} & \multirow{3}{*}{0.230} \\
\hline Yes & $45(83.3 \%)$ & $26(92.9 \%)$ & & & & & \\
\hline No & $9(16.7 \%)$ & $2(7.1 \%)$ & & & & & \\
\hline \multicolumn{3}{|l|}{ Centile } & \multirow{3}{*}{6.7} & \multirow{3}{*}{2.267} & \multirow{3}{*}{19.889} & \multirow{3}{*}{13.277} & \multirow{3}{*}{0.001} \\
\hline$<$ Third centile & $07(13.0 \%)$ & $14(50.0 \%)$ & & & & & \\
\hline$<$ Tenth centile & $47(87.0 \%)$ & $14(50.0 \%)$ & & & & & \\
\hline
\end{tabular}

Table 4: Doppler and percentile of FGR with Amniotic fluid index.

\begin{tabular}{|c|c|c|c|c|c|c|}
\hline & \multicolumn{4}{|c|}{ Amniotic fluid index } & Chi square & p value \\
\hline Doppler & $<5 \mathrm{~cm}$ & $5-8 \mathrm{~cm}$ & $8-10 \mathrm{~cm}$ & $>10 \mathrm{~cm}$ & \multirow{3}{*}{10.004} & \multirow{3}{*}{0.019} \\
\hline Normal & $0(0.0 \%)$ & $7(53.8 \%)$ & $15(68.2 \%)$ & $3274.4 \%)$ & & \\
\hline Abnormal & $4(100.0 \%)$ & $6(46.2 \%)$ & $7(31.8 \%)$ & $11(25.6 \%)$ & & \\
\hline \multicolumn{5}{|l|}{ Percentile } & \multirow{3}{*}{14.491} & \multirow{3}{*}{0.002} \\
\hline$<$ Third centile & $4(100.0 \%)$ & $5(38.5 \%)$ & $4(18.2 \%)$ & $8(18.6 \%)$ & & \\
\hline$<$ Tenth centile & $0(0.0 \%)$ & $8(61.5 \%)$ & $18(81.8 \%)$ & $35(81.4 \%)$ & & \\
\hline
\end{tabular}

\section{Comparison of significant variables with Doppler}

Table 5: Comparison chart between Doppler normal and abnormal group.

\begin{tabular}{|llll|}
\hline Variable & $\begin{array}{l}\text { Doppler } \\
\text { normal } \\
(\mathbf{n = 5 4})\end{array}$ & $\begin{array}{l}\text { Doppler } \\
\text { abnormal } \\
(\mathbf{n = 2 8})\end{array}$ & $\begin{array}{l}\text { Significance } \\
\text { (p value) }\end{array}$ \\
$\begin{array}{l}\text { Gestational age at } \\
\text { diagnosis (mean) } \\
\text { in weeks }\end{array}$ & 35.19 & 34.29 & 0.032 \\
\hline $\begin{array}{l}\text { Gestational age at } \\
\text { delivery (mean) in } \\
\text { weeks }\end{array}$ & 36.29 & 35.76 & 0.297 \\
$\begin{array}{l}\text { Mean birth } \\
\text { weight of } \\
\text { neonate (g) }\end{array}$ & 2201.80 & 1929.46 & 0.001 \\
\hline $\begin{array}{l}\text { NICU stay } \\
\text { (days) }\end{array}$ & 5.00 & 8.04 & 0.003 \\
\hline
\end{tabular}

The gestational age at diagnosis (mean) in weeks was compared in Doppler normal and Doppler abnormal and FGR was diagnosed earlier by nearly a week with significant $\mathrm{p}$ value. $\mathrm{p}$ value was not significant in the gestational age at delivery in weeks of the two groups. The mean birthweight in Doppler abnormal was 272.34 grams lesser than in Doppler normal group ( $\mathrm{p}$ value 0.001). Perinatal morbidity in terms of NICU days (mean) was highly significant implying that growth restricted foetuses with Doppler pattern abnormality stayed mean of 3 days more than the Doppler normal group. (p value:0.003).

\section{DISCUSSION}

Incidence of FGR was $10.35 \%$ in present study. National perinatal database reported the incidence of IUGR to be $9.65 \%$ among new born. ${ }^{12}$ de Onis $\mathrm{M}$ opined that the 
IUGR rate in developing countries is six times higher than in developed ones, and it is estimated that $23.8 \%$ of all new-born infants, $\sim 30$ million, are born with IUGR every year worldwide. ${ }^{13}$ In Chandra and Mathews, reported incidence of IUGR to be $14.1 \% .^{14}$

Majority of mothers were in 25-34 age group (90.2\%) similar to Singh A et al and Satyavrathan V et al. ${ }^{15,16} 57 \%$ were multipara in Satyavrathan $\mathrm{V}$ et al similar to ours $(58 \%) .{ }^{16}$ Infertility treated subjects were $29.3 \%$ as in Seal A et al. ${ }^{17}$ Ghazi et al also in his study noted the increased incidence of infertility in FGR. ${ }^{18}$ Those women with past history of spontaneous abortion were 2.21 times more likely to have an IUGR baby compared to women without such history in Motghare DD et al. ${ }^{19} 30 \%$ in ours. Recurrence FGR risk is described in Bassetty $\mathrm{K} \mathrm{C}$ et al as in present study. ${ }^{20}$ Referrals with FGR were $26.8 \%$ similar to that in Singh A et al. ${ }^{15}$

Hypertensive disorders of Pregnancy (24.39\%), thyroid dysfunction $(21.95 \%)$, anaemia $(19.51 \%)$ and Gestational diabetes $(14.63 \%)$ were noted in FGR mothers similar to Satyavrathan V et al and Sharma et al. ${ }^{16,21}$ Motghare DD et al, Bassetty $\mathrm{KC}$ and Jamal $\mathrm{M}$ et al described gestational hypertension and anaemia as maternal determinants of FGR. ${ }^{19,20,22}$

Caesarean delivery was $75.60 \%$ and $67 \%$ of them were electives in present study similar to Seal A et al ${ }^{17}$ with $68 \%$ lower segment caesareans and $54 \%$ electives. $24 \%$ of women delivered vaginally compared to $32 \%$ as in Seal A et al. ${ }^{17}$ Impending Eclampsia, HELLP syndrome and Eclampsia, accounted for $9.75 \%$ of terminations. The most common indication for LSCS in Sinha et al was found to be abnormal Doppler findings (23.72\%) followed by severe oligohydramnios $(22.03 \%)$ and fetal distress (18.64 \%) which is observed in Raja Rajeswari et al and in present study. ${ }^{23,24}$

As with Seal et al, majority (64\%) of FGR were diagnosed between $32-34$ weeks in this study. ${ }^{17}$ In Lekshmi et al, $60 \%$ of the FGR were born to mothers $<37$ weeks and $29 \%<32$ weeks, while in ours, $52 \%$ were born term and $32 \%$ were born 34-36.6 weeks. ${ }^{25}$ The mean GA at FGR diagnosis in normal Doppler group was 35.19 weeks and 34.29 weeks in abnormal Doppler ( $p$ value 0.03 ) and was statistically significant. In Malhotra et al, GA at diagnosis was 26.4 weeks in abnormal Doppler group and 28 weeks in normal Doppler group ( $\mathrm{p}$ value $0.001){ }^{26}$ Also, the mean GA at delivery in Doppler abnormal group was 27.2 and 37 weeks in Doppler normal group, while this variable was not statistically significant in present study. The diagnosis to delivery interval was 46 days, 38 days and 23 days in mild, moderate and severe placental insufficiency according to Turan et al. ${ }^{10}$ In present study $33 \%$ delivered in $48 \mathrm{hrs}$, $39 \%$ in a week, and $28 \%$ waited $>14$ days.

Birthweight from 2-2.499 kg constituted 53 neonates $(64.63 \%)$ followed by $1.5-1.999 \mathrm{~kg}(23.17 \%)$ in this study. Satyavrathan $\mathrm{V}$ et al and Rekha et al in their study on FGR had $82 \%$ and $91.7 \%$ neonates in $1.5-2.5 \mathrm{~kg}$ category similar to $87.8 \%$ in present study. ${ }^{16,27}$ The mean birth weight was $2201.80 \mathrm{~g}$ in Doppler normal FGR and it was $1929.46 \mathrm{~g}$ in abnormal Doppler and this difference was statistically significant ( $p$ value-0.001) and was similar to Malhotra et al where birth weight of FGR with abnormal Doppler was $742 \pm 126 \mathrm{~g}$ and in neonates with normal Doppler was $1680 \pm 259 \mathrm{~g}$ and this difference was statistically significant $(\mathrm{P}=0.0001) .{ }^{26}$ So FGR with no Doppler abnormalities had significantly better birthweights than abnormal Doppler ( $p$ value- 0.0009). In a study by Sinha et al, the mean birth weight was found maximum (1958 g) in the group with normal Doppler findings (33\% cases) and minimum (1519 gm) in those with abnormal Doppler which similar to present study. ${ }^{23}$ This is also in accordance with who demonstrated that foetuses with lower birth weight had associated Doppler abnormality. ${ }^{28}$ There was significance in EBW and original birthweights ( $p$ value:0.004) in this study. Female babies were more likely to be growth restricted compared to male babies consistent with the study by Seal A et al. ${ }^{17}$

Gestational age at delivery and NICU stay were compared and it was found that neonates born at term had shorter NICU stays than very preterm neonates. Also, FGR with normal Doppler had shorter NICU stays than FGR neonates with Doppler abnormalities ( $p$ value0.003 ) similar to Rekha $\mathrm{BR}$ et al (P value-0.003). ${ }^{27}$ Baschat et al found that gestational age at delivery was a strong determinant of neonatal outcome using Obstetric Doppler. ${ }^{28} \mathrm{NICU}$ admissions in our hospital were $86.58 \%$ similar to Rekha BR et al $77.8 \%$ and Ebrashy et al $66 \% .^{27,29} 22.5 \%$ of our neonates had need to resuscitate as $19.6 \%$ in Satyavrathan V et al. ${ }^{16}$ Thomas JS et al opined that FGR with abnormal Doppler had an early delivery, increased NICU admission, need for ventilation than those with normal Doppler. ${ }^{30} 57.15 \%$ neonates $<37$ weeks needed NICU admissions in Rekha BR et al as $53 \%$ in present study. ${ }^{27}$ Neonatal hyperbilirubinemia $32.39 \%$, respiratory distress $21.12 \%$, sepsis $19.71 \%$ were similar to Baschat et al with neonatal sepsis $39 \%$, hyperbilirubinemia $31 \%$ and respiratory distress $15 \% .^{28}$ According to Pallotto et al, perinatal asphyxia, hypothermia, hypoglycaemia and hypocalcaemia are common in IUGR babies. ${ }^{31}$

All 4 cases of severe oligohydramnios $(\mathrm{AFI}<5)$ with CPR $<1$, birthweight centile $<3^{\text {rd }}$ had abnormal Doppler and were resuscitated. Severe oligamnios with Doppler abnormality (p value-0.002) had adverse perinatal outcomes consistent with Rutherford et al. ${ }^{32}$ All newborns had an Apgar >7 in present study and there was no intrapartum stillbirths or neonatal deaths due to better surveillance, timely delivery and state of art NICU care. Abnormal BPP foetuses had significant Doppler pattern abnormalities (OR:14.2). The inverse relationship between abnormal BPP scores and presence of fetal distress, FGR, NICU admissions were described by 
Manning et al. ${ }^{33}$ Cosmi et al showed that, in IUGR foetuses delivered at 32 weeks, the integration of Doppler and neonatal outcome was statistically correlated with BPP. ${ }^{34}$ FGR foetus with nonreactive NST had 3.5 times the chance of Doppler pattern abnormalities in contrast to Grivell RM who reported that NST had no significant effect on perinatal morbidity. ${ }^{35}$ As Gestational age advances there is a significant decrease in the number of new-borns with Doppler abnormalities. (p value-0.023). Severe FGR multiplied the risk to have abnormalities in Doppler pattern by 6.7 times (p value - 0.001). Perinatal morbidity worsened, with lower birthweights, Doppler abnormality, remote from term and hypertension. ${ }^{10}$

\section{CONCLUSION}

Abnormal Doppler velocimetry is significantly associated with earlier FGR detection, shorter decision- delivery interval, reduction in the mean birthweight and a longer NICU stay. Hence, Umbilical artery Doppler and Cerebroplacental index is an integral part of in-utero fetal surveillance to identify impending fetal hypoxia, appropriate management and optimising the timing of delivery and improve perinatal health in FGR.

\section{ACKNOWLEDGMENTS}

Authors would like to thank the Department of Obstetrics and Gynaecology and Department of Radiodiagnosis Travancore Medical College for their cooperation and support and all the patients without whom this study might not have been materialized.

Funding: No funding sources

Conflict of interest: None declared

Ethical approval: The study was approved by the Institutional Ethics Committee

\section{REFERENCES}

1. Cochran WD, Lee KG. Assessment of the new-born. Manual of Neonatal Care. $5^{\text {th }}$ ed. Philadelphia: Lippincott Williams and Wilkins; 2004.

2. Unterscheider J, O’Donoghue K, Daly S, Geary MP, Kennelly MM, McAuliffe FM, et al. Fetal growth restriction and the risk of perinatal mortality-case studies from the multicentre PORTO study. BMC Preg Childbirth. 2014;14(1):63.

3. Fetal growth disorders. In Williams Obstetrics. $24^{\text {th }}$ ed. New York, NY: Mc Graw Hill; 2013:872-890.

4. Fitzhardinge PM, Steven EM. The small-for-date infant. II. Neurological and intellectual sequelae. Pediatrics. 1972;50(1):50-7.

5. Figueras F, Gratacos E. Update on the diagnosis and classification of fetal growth restriction and proposal of a stage-based management protocol. Fetal Diagn Ther. 2014;36(2):86-98.

6. Bilardo CM, Wolf H, Stigter RH, Ville Y, Baez E, Visser GH, Hecher K. Relationship between monitoring parameters and perinatal outcome in severe, early intrauterine growth restriction. Ultrasound Obstet Gynecol. 2004;23:119-25.

7. Gagnon R, Van Den HM. The use of foetal Doppler in obstetrics. J Obstet Gynaecol Can. 2003;25(7):601-14.

8. Lakhkar BN, Rajagopal KV, Gourisankar PT. Doppler prediction of adverse perinatal outcome in PIH and IUGR. Indian Radiol Imag. 2006;16(1):109.

9. Bano S, Chaudhary V, Pandey S, Mehta VL, Sharma AK. Color Doppler evaluation of cerebral-umbilical pulsatility ratio and its usefulness in the diagnosis of intrauterine growth retardation and prediction of adverse perinatal outcome. Indian J Radiol Imaging. 2010;20:20-5.

10. Turan OM, Turan S, Gungor S, Berg C, Moyano D, Gembruch U, et al. Progression of Doppler abnormalities in intrauterine growth restriction: Ultrasound Obstet Gynecol. 2008;32:160-7.

11. Savchev S, Figueras F, Cruz Martinez R. Estimated weight centile as a predictor of perinatal outcome in small-for-gestational-age fetuses with normal umbilical, brain and uterine Doppler. Ultrasound Obstet Gynecol. 2012;39:299-303.

12. Fanaroff AA, Hack M, Walsh MC. The NICHD neonatal research network: changes in practice and outcomes during the first 15 years. Semin Perinatol. 2003;27(4):281-7.

13. de Onis M, Blossner M, Villar J. Levels and patterns of intrauterine growth retardation in developing countries. Eur J Clin Nutr 1998;52(suppl 1):S5-S15.

14. Chandra S, Mathews SC. Perinatal morbidity and mortality in low birthweight babies. J Obstet Gynaecol India. 2003:53(3):237.

15. Singh A, Ambujam K. Maternal socio-demographic determinants and fetal outcome of intrauterine growth restriction. Int $\mathbf{J}$ Reprod Contracept Obstet Gynecol. 2018;7:3843-7.

16. Satyavrathan V, Ahmed N, Sundrappa S. Study of perinatal outcomes of pregnancies with intrauterine growth restriction in a tertiary care centre in North Kerala. J Evid Based Med Healthc. 2017;4(37):22038.

17. Seal A, Dasgupta A, Sengupta M, Dastider R, Sen S. Analysis of fetal growth restriction in pregnancy in subjects attending in an obstetric clinic of a tertiary care teaching hospital. Int $\mathrm{J}$ Reprod Contracept Obstet Gynecol. 2018;7:973-80.

18. Ghazi HA, Spielberger C, Kallen B. Delivery outcome after infertility: a registry study. Fertil Steril. 1991;55:726-32.

19. Motghare DD, Frederick SV, Pawaskar M, Kulkarni MS. Maternal determinants of intrauterine growth restriction in Goa, India: a case-control study. Global J Medic Public Health. 2014;3(1):O8.

20. Bassetty KC, Phukan P, Ahmed RD, Borah R. Outcomes of Neonates in Pregnancies with Intrauterine Growth Restriction in Developing Countries: A Cross-sectional Study Over a Period of 6 Months. Gynecol Obstet (Sunnyvale). 2017;7:434. 
21. Sharma DD, Chandnani KC. Clinical study of IUGR cases and correlation of Doppler parameters with perinatal outcome. Int J Reprod Contracept Obstet Gynecol. 2016;5:4290-6.

22. Jamal M, Khan N. Maternal factors associated with low birth weight. J Coll Physicians Surge Pak. 2003;13:25-8.

23. Sinha S, Kurude VN. Study of obstetric outcome in pregnancies with intrauterine growth retardation. Int J Reprod Contracept Obstet Gynecol. 2018;7:185863.

24. Rajarajeswari R, Thendral V. Prediction of perinatal outcome with umbilical artery Doppler in IUGR fetuses- a prospective analytical study in a tertiary medical college in Tamilnadu, India. Int $\mathrm{J}$ Reprod Contracept Obstet Gynecol. 2017;6:1097-104.

25. Lakshmi V, Indira K, Neeraja M, Rao PC. Role of Doppler in pregnancy induced hypertension and IUGR. Int J Res Health Sci. 2015;3(1):191-8.

26. Malhotra N, Chanana C, Kumar S, Roy K, Sharma JB. Comparison of perinatal outcome of growthrestricted fetuses with normal and abnormal umbilical artery Doppler waveforms. Indian J Med Sci. 2006;60(8):311-7.

27. Rekha BR, Pavanaganga A, Lakshmi SMPA, Nagarathnamma R. Comparison of Doppler findings and neonatal outcome in fetal growth restriction. Int J Reprod Contracept Obstet Gynecol. 2017:6:955-8.

28. Baschat AA, Cosmi E, Bilardo CM, Wolf H, Berg C, Rigano S, et al. Predictors of neonatal outcome in early-onset placental dysfunction. Obstet Gynecol. 2007;109:253-61.

29. Ebrashy A, Azmy O, Ibrahim M, Waly M, Edris A. Middle cerebral/umbilical artery resistance index ratio as sensitive parameter for fetal well-being and neonatal outcome in patients with preeclampsia: case-control study. Croatian Med J. 2005;46(5).

30. Thomas JS, Malliga A, Sethurajan S. Significance of umbilical artery Doppler velocimetry in the perinatal outcome of growth restricted fetuses. Int J Reprod Contracept Obstet Gynecol. 2018;7:1074-8.

31. Pallotto EK, Kilbride HW. Perinatal outcome and later implications of intrauterine growth restriction. Clinical Obstet Gynecol. 2006;49(2):257-69.

32. Rutherford SE, Phelan JP, Smith CV, Jacobs N. The four-quadrant assessment of amniotic fluid volume: an adjunct to antepartum fetal heart rate testing. Obstet Gynecol. 1987;70(3 Pt 1):353-6.

33. Manning FA, Harman CR, Morrison I, Menticoglou SM, Lange IR, Johnson JM. Fetal assessment based on fetal biophysical profile scoring. IV.An analysis of perinatal morbidity and mortality. Am J Obstet Gynecol. 1990;162(3):703-9.

34. Cosmi E, Ambrosini G, D'antona D, Saccardi C, Mari G. Doppler, cardiotocography, and biophysical profile changes in growth restricted fetuses. Obstet Gynecol. 2005;106:1240-5.

35. Grivell RM, Alfirevic Z, Gyte GM, Devane D. Antenatal cardiotocography for fetal assessment. Cochrane Database Syst Rev. 2010;1.

Cite this article as: Shenoy HT, James SX, Shenoy ST. Maternal risk factors and perinatal outcomes in fetal growth restriction using obstetric Doppler in South Kerala, India. Int J Reprod Contracept Obstet Gynecol 2019;8:6-13. 